\title{
A literature review of cost-effectiveness of intravenous recombinant tissue plasminogen activator for treating acute ischaemic stroke
}

To cite: Joo H, Wang G, George MG. A literature review of cost-effectiveness of intravenous recombinant tissue plasminogen activator for treating acute ischaemic stroke. Stroke and Vascular Neurology 2017;2:e000063. doi:10.1136/ svn-2016-000063

Received 13 December 2016 Revised 4 February 2017 Accepted 6 February 2017 Published Online First 28 April 2017
CrossMark

${ }^{1}$ Division for Heart Disease and Stroke Prevention, CDC; IHRC Inc., Atlanta, Georgia, USA

${ }^{2}$ Division for Heart Disease and Stroke Prevention, CDC, Atlanta, Georgia, USA

Correspondence to Dr Guijing Wang; gbw9@cdc.gov

\section{ABSTRACT}

Background Intravenous recombinant tissue plasminogen activator (IV rtPA) is recommended treatment for patients with acute ischaemic stroke, but the cost-effectiveness of IV rtPA within different time windows after the onset of acute ischaemic stroke is not well reviewed.

Aims To conduct a literature review of the costeffectiveness studies about IV rtPA by treatment times.

Summary of review A literature search was conducted using MEDLINE, EMBASE, CINAHL and Cochrane Library, with the keywords acute ischemic stroke, tissue plasminogen activator, cost, economic benefit, saving and incremental cost-effectiveness analysis. The review is limited to original research articles published during 1995-2016 in English-language peer-reviewed journals. We found 16 studies meeting our criteria for this review. Nine of them were cost-effectiveness studies of IV rtPA treatment within 0-3 hours after stroke onset, 2 studies within 3-4.5 hours, 3 studies within 0-4.5 hours and 2 studies within 0-6 hours. IV rtPA is a cost-saving or a costeffectiveness strategy from most of the study results. Only one study showed incremental cost-effectiveness ratio of IV rtPA within 1 year was marginally above US $\$ 50000$ per quality-adjusted life year threshold. IV rtPA within $0-3$ hours after stroke led to cost savings for lifetime or 30 years and IV rtPA within 3-4.5 hours after stroke increased costs but still was cost-effective.

Conclusions The literature generally showed that IV rtPA was a dominant or a cost-effective strategy compared with traditional treatment for patients with acute ischaemic stroke without IV rtPA. The findings from the literature lacked generalisability because of limited data and various assumptions.

\section{INTRODUCTION}

Stroke is a serious brain injury that can result in permanent disability and death. The burden of stroke, including the absolute numbers of incidence and death, increased during the last decade. ${ }^{1}$ Globally, an estimated 33 million strokes occurred and 5.8 million individuals died from stroke in $2010 .^{12}$ In addition, around 5 million stroke survivors have permanent disability. ${ }^{2}$ In 2010 , the estimated total cost of stroke, including direct medical cost and indirect cost, was
US $\$ 53.9$ billion in the USA and $€ 64.1$ billion in Europe. ${ }^{34}$ Approximately $70 \%$ of strokes are ischaemic worldwide, while the proportion of ischaemic stroke varies by race/ ethnicity and region. ${ }^{15}$

To reduce the burden associated with stroke, investigations of cost-effectiveness of available treatments for patients with stroke such as intravenous (IV) injection of recombinant plasminogen activator (rtPA) are necessary. Since the US Food and Drug Administration (FDA) approval in 1996, rtPA remains the only thrombolytic agent approved for acute ischaemic stroke in the USA. ${ }^{6}$ IV rtPA has been shown to improve health outcomes after stroke. $^{78}$

In the past two decades, there have been some cost-effectiveness studies on IV rtPA. For instance, Fagan et al showed that IV rtPA within 3 hours after the onset of stroke saved cost associated with stroke treatment as well as improved outcomes from stroke in their 1998 study. ${ }^{9}$ Additionally, we found three review articles on the cost-effectiveness of IV rtPA for acute ischaemic stroke. ${ }^{10-12}$ All of them reviewed studies published prior to $2008 .^{10-12}$ Since the new guidelines of IV rtPA between 3 and 4.5 hours after the onset of acute ischaemic stroke from the American Heart Association/American Stroke Association (AHA/ASA) as well as similar new recommendations from other organisations in Europe or Australia were released in late 2000s and early 2010s, ${ }^{13-16}$ and the cost-effectiveness of IV rtPA for the extended time windows, within 4.5 hours after the onset of stroke, has never been examined, an up-to-date review of economic impact of IV rtPA is needed to better understand the cost-effectiveness of IV rtPA under various treatment conditions. Thus, we conducted a literature review of cost-effectiveness of IV rtPA published up to 2014. 


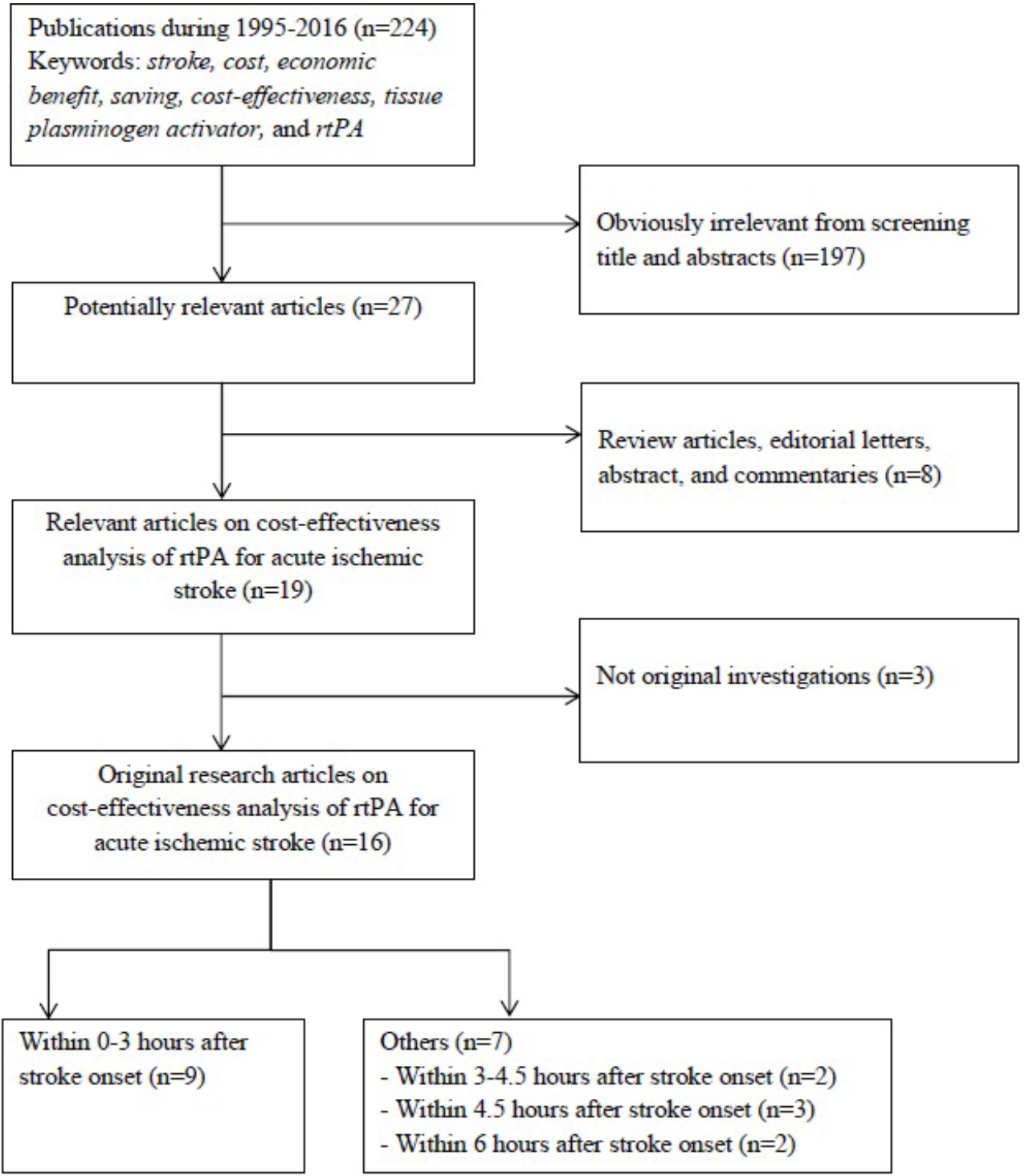

Figure 1 Selection of studies on cost-effectiveness analysis of recombinant tissue plasminogen activator (rtPA) for acute ischaemic stroke.

\section{METHODS}

We performed a comprehensive literature search of peer-reviewed journal articles published in English between January 1995 and December 2016 by using the databases MEDLINE, EMBASE, CINAHL and Cochrane Library. We augmented the search by using Google Scholar and checking the references of the articles we obtained. The strategy used for the search included keywords in stroke and rtPA treatment including acute ischemic stroke, tissue plasminogen activator and rtPA, and keywords in cost-effectiveness analyses including cost, economic, benefit, effectiveness and ICER (incremental cost-effectiveness analysis).

Figure 1 depicts the process of literature selection for this review. The initial search yielded 224 abstracts. By screening of titles and abstracts, 197 studies were excluded because they were not cost-effectiveness studies or because they were about supporting strategies to increase the usage of IV rtPA, such as telemedicine or air transportation for patients with stroke, and thus were excluded. In addition, review articles, editorial letters, abstracts and commentaries were excluded $(n=8)$. We completed full-text review of all articles that passed the initial titles and abstracts review and finalised the set of original research articles $(n=16)$ for this study by further excluding three studies that were not original cost-effectiveness studies. Cost-effective analysis is an economic evaluation method comparing both costs and health outcomes of alternative interventions. ${ }^{17}$ Common health outcomes used in the literature include quality-adjusted life years (QALYs), life years gained, number of cases prevented and mortality. ${ }^{17}$ QALYs, which were developed in 1960s for cost-effectiveness analyses, are measures of health considering both mortality and morbidity. QALYs are valued between 0 and 1 per year, meaning 0 as death and 1 as perfect health. ${ }^{18}$ Cost-effectiveness analysis using QALYs is also called as cost-utility analysis. ${ }^{19}$ ICER, the main estimate in a cost-effectiveness analysis, is derived 
Incremental Costs

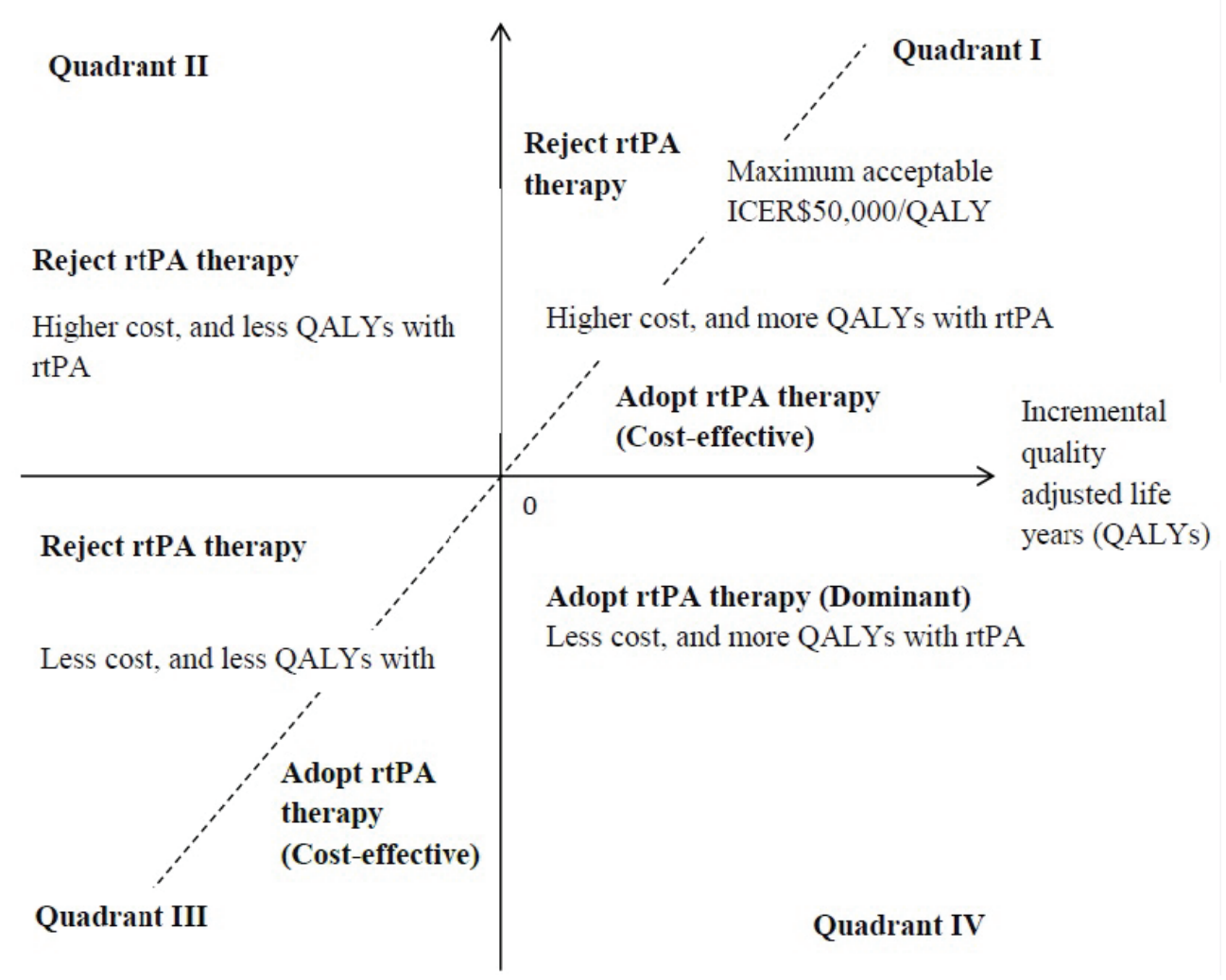

Figure 2 Conceptual framework of cost-effectiveness of recombinant tissue plasminogen activator (rtPA) therapy. ICER, incremental cost-effectiveness analysis; QALY, quality-adjusted life year.

by the difference in costs over the difference in health outcomes between alternative interventions. In this review, ICER is the difference in cost between IV rtPAtreated group and non-IV rtPA group, that is, incremental cost, over the differences in QALYs between them, that is, incremental QALYs.

We analysed the literature by ${ }^{1}$ : model structure and main data sources, ${ }^{2}$ study results and ${ }^{3}$ major limitations. For model structure and data sources, we examined perspective, modelling method, and intervention type, and main source of economic and clinical data. For study results, we summarised the cost-effectiveness results by various study time windows, time horizon, net-cost savings, QALYs gained and ICER. Major limitations mentioned in each study were also summarised.

We used a cost-effectiveness quadrant diagram to demonstrate the costs and outcomes of an IV rtPA strategy compared with a non-rtPA strategy (figure 2). The horizontal axis represents incremental QALYs associated with IV rtPA and the vertical axis represents the incremental cost associated with IV rtPA. For instance, the negative numbers in the vertical axis means that cost for a patient who received IV rtPA were lower than the cost for a patient who did not receive IV rtPA. When an estimated ICER is located in quadrant IV (lower right), IV rtPA is a cost-saving or a dominant strategy, that is, higher QALYs with less cost. When an estimated ICER is located in quadrant I or III, the acceptance decision depends on value of the estimated ICER and an ICER threshold. In this paper, we used US\$50000/QALY as a reference threshold. ${ }^{20}$ If the estimated ICER is below the threshold, that is, located under the dotted line in figure 2, we define that IV rtPA is a cost-effective strategy and adopt the IV rtPA strategy.

To compare ICERs from different countries, we derived 2014 US dollar value from all studies, which did not report ICERs in US dollars, by using consumer price indices (CPI) from the World Bank and purchasing power parity (PPP) exchange rate in 2014 from the Organisation for Economic Cooperation and Development (OECD) ${ }^{21-23}$ The 2014 US dollar value was derived by multiplying CPI in 2014 at a study country by incremental costs from a study, divided by CPI in a study year at a study country, and divided by a PPP exchange rate (national currency of study country per US dollar) in 2014 (ncremental costs from a study $\times$ (CPI in 2014 at a study country/CPI in a study year at a study country)/PPP exchange rate). When a study reported multiple ICERs from different time periods, we included ICERs from both a short-term (1 year) and a long-term (30 years or a lifetime) time period.

\section{RESULTS}

Among 15 original articles reviewed, six studies were from the US, ${ }^{94-28}$ two from the United Kingdom (UK), ${ }^{29}{ }^{30}$ two from Australia, ${ }^{31} 32$ two from China, ${ }^{334}$ and one each from Canada, ${ }^{35}$ New Zealand, ${ }^{36}$ Denmark, ${ }^{37}$ and Spain. ${ }^{38}$ Nine 
of them used the payers' perspective or healthcare system perspective, and four studies used the societal perspective while two studies did not clearly mention it.

In table 1, nine of 15 studies investigated the cost-effectiveness of IV rtPA therapy within 0-3 hours after stroke onset, ${ }^{9} 2426283032353738$ two studies within 3-4.5 hours, ${ }^{25} 27$ three studies within $0-4.5$ hours, ${ }^{313436}$ and one study within 0-6 hours ${ }^{29}{ }^{33}$ (figure 1). The first study that examined cost-effectiveness of IV rtPA was published in 1998, two years after the FDA approval. ${ }^{9}$ Eight out of 16 studies were published between 2011 and 2016. Among them, the five studies were the studies of IV rtPA within 3-4.5 hours or $0-4.5$ hours after the onset of stroke. ${ }^{25} 27313436$ The remaining three studies published during this period were US studies looking at the $0-3$ hours time window to investigate up-to-date cost-effectiveness of IV $\mathrm{rtPA}^{24}$ or state specific cost-effectiveness of IV rtPA, ${ }^{26}$ and Chinese study examining the 0-6hours cost-effectiveness of IV rtPA. $^{33}$

The reviewed studies used various sources of data for analyses. Main data sources were published data or literature. When published data were not available, data from hospitals or panel survey data were used. ${ }^{3038}$ For economic data, 10 studies used both previously published literature and data from their own collection or analyses. Three studies used previously published literature data only and two studies used data from the authors' own collection or analyses. For clinical data, only five studies used data from both sources. In addition, three studies were from a small community-based study.

All studies consistently showed that IV rtPA improved QALYs (table 2), even some showing marginal improvement of QALYs. Sinclair et $a l^{35}$ showed exceptionally high improvement of QALYs associated with IV rtPA (3.46 QALYs per patient). Because of the complexity of the cost-effectiveness model and multiple input sources, there could be multiple reasons of high QALYs improvement in this study.

The impact of IV rtPA on cost was ambiguous and varied by time window and study time horizon. In the USA, two of the six studies examined the cost-effectiveness of IV rtPA within the 3-4.5 hours time window. Use of IV rtPA within 3-4.5 hours after the onset of stroke increased costs (US\$1495-US\$6050) but improved QALYs (0.240.28 ) over the lifetime. The estimated ICERs (US\$6255/ QALY-US\$21978/QALY) showed the therapy was cost-effective using the US $\$ 50000 /$ QALY threshold. The remaining four studies in the USA showed that IV rtPA within 0-3 hours after onset of stroke was a dominant strategy, that is, cost saving and QALYs gained.

The results from non-US studies using IV rtPA within 0-3 hours were consistent with the results from the US studies. One exception, which showed an ICER marginally above an ICER threshold of US $\$ 50000 /$ QALY at the first year (US\$55591/QALY), is the Danish study by Ehlers $e t$ al that examined a range of time periods and showed that IV rtPA within 0-3hours after the onset of stroke with 24 hours in-house MRI imaging and neurology coverage increased cost for the first and the second year after stroke. ${ }^{37}$ IV rtPA, however, became a dominant strategy after the third year and the 30 years estimates also indicated the IV rtPA as a dominant strategy. ${ }^{37}$ Results from three non-US studies examining the cost-effectiveness of IV rtPA within 0-4.5 hours showed that IV rtPA increased cost but was cost-effective with an ICER threshold of US\$50000/QALY. The UK study by Sandercock $e t$ al showed that IV rtPA within 6 hours of symptom onset increased cost and the ICER was $£ 13581 /$ QALY (US $\$ 25045 /$ QALY in 2012) for the first year after the stroke, but over the lifetime the therapy was a dominant strategy. ${ }^{29}$ The Chinese study by Yan et al also showed that IV rtPA within 6 hours increased both cost and utility and cost-effective within 14 days after the stroke. ${ }^{33}$

All of the ICERs were located in quadrant I or IV (figure 3). Lifetime ICERs of IV rtPA within 0-3 hours or $0-4.5$ hours were located in quadrant IV, and therefore using IV rtPA was a dominant strategy. The ICER of IV rtPA within 0-3 hours from Sinclair et $a l^{35}$ is not shown in figure 3 because of space limitation but the ICER was located in quadrant IV. The ICERs from studies that examined IV rtPA within 3-4.5 hours were located in quadrant I and under the threshold line, thus IV rtPA was a cost-effective strategy in this scenario. The impact of IV rtPA on cost in the first year was ambiguous, but IV rtPA was still a short-term dominant or a cost-effective strategy from most studies.

We summarised major limitations of the literature (table 3). The most common limitation was insufficient data for accurate cost-effectiveness estimates. Some studies mentioned a lack of generalisability because of data limitations. ${ }^{24-26} 283335$ It was also pointed out that some studies used multiple data sources because of limited data. ${ }^{245}$ Lack of long-term mortality and cost data as well as insufficient up-to-date outcome and cost data were also mentioned as limitations. ${ }^{24} 2637$

\section{DISCUSSION}

This review investigated studies about cost-effectiveness of IV rtPA for treating patients with acute ischaemic stroke. IV rtPA within 0-3 hours after the onset of stroke was cost-saving while improving QALYs during lifetime. The finding about the cost-effectiveness of IV rtPA within 0-3 hours after the onset of stroke is consistent with previous reviews. ${ }^{10-12}$ However, the most recent review was published before AHA/ASA released the updated guidelines with extended time window. In the review, we found that IV rtPA within $0-4.5$ hours or within 3-4.5 hours after the onset of stroke was cost-saving or cost-effective. Although some studies showed that IV rtPA within $0-4.5$ hours or within 3-4.5 hours after the onset of stroke increased cost, it was a cost-effective strategy. The review results emphasise the importance of reducing door-toneedle time for patients with acute ischaemic stroke. 


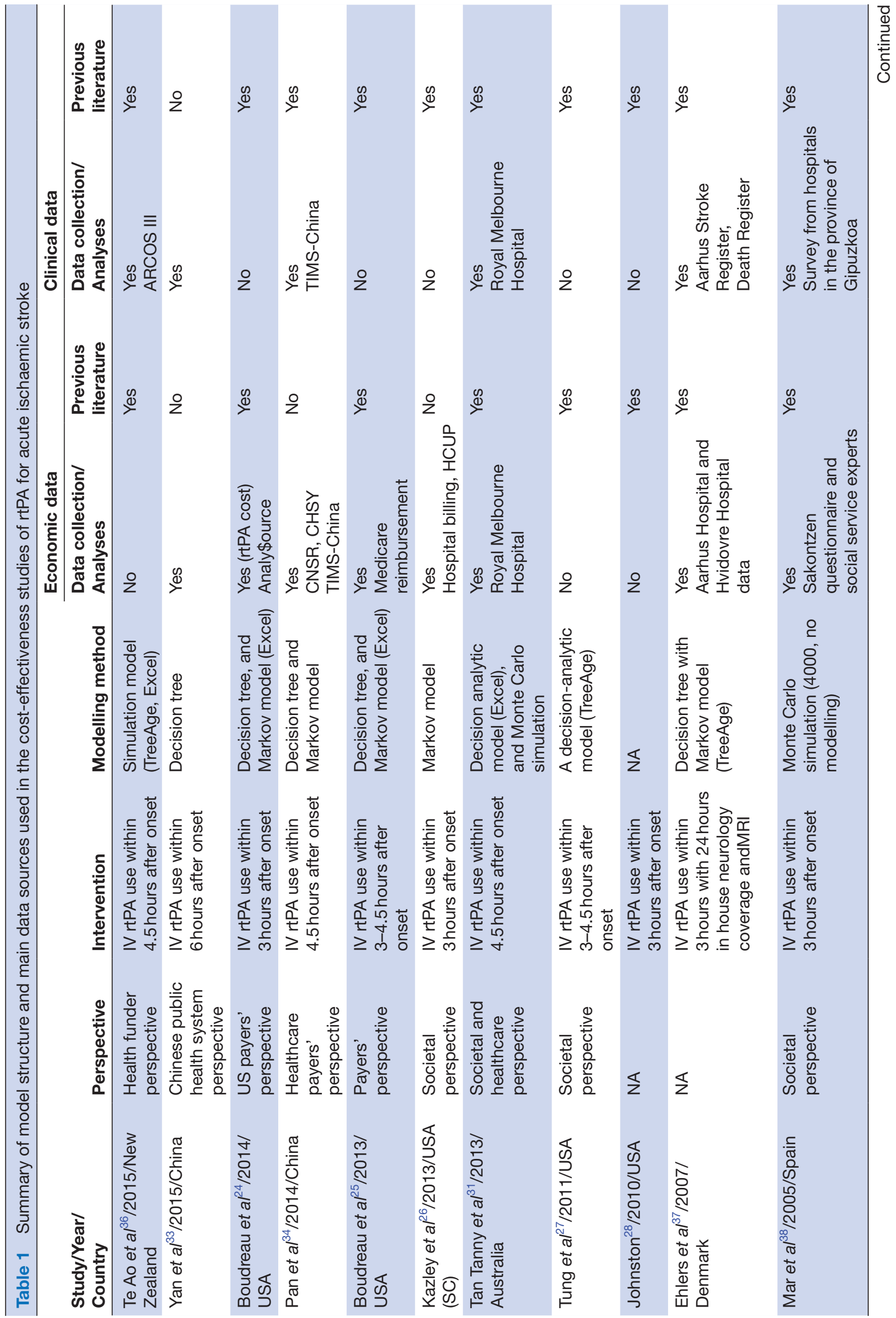

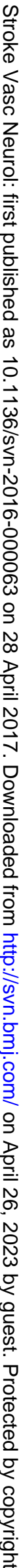




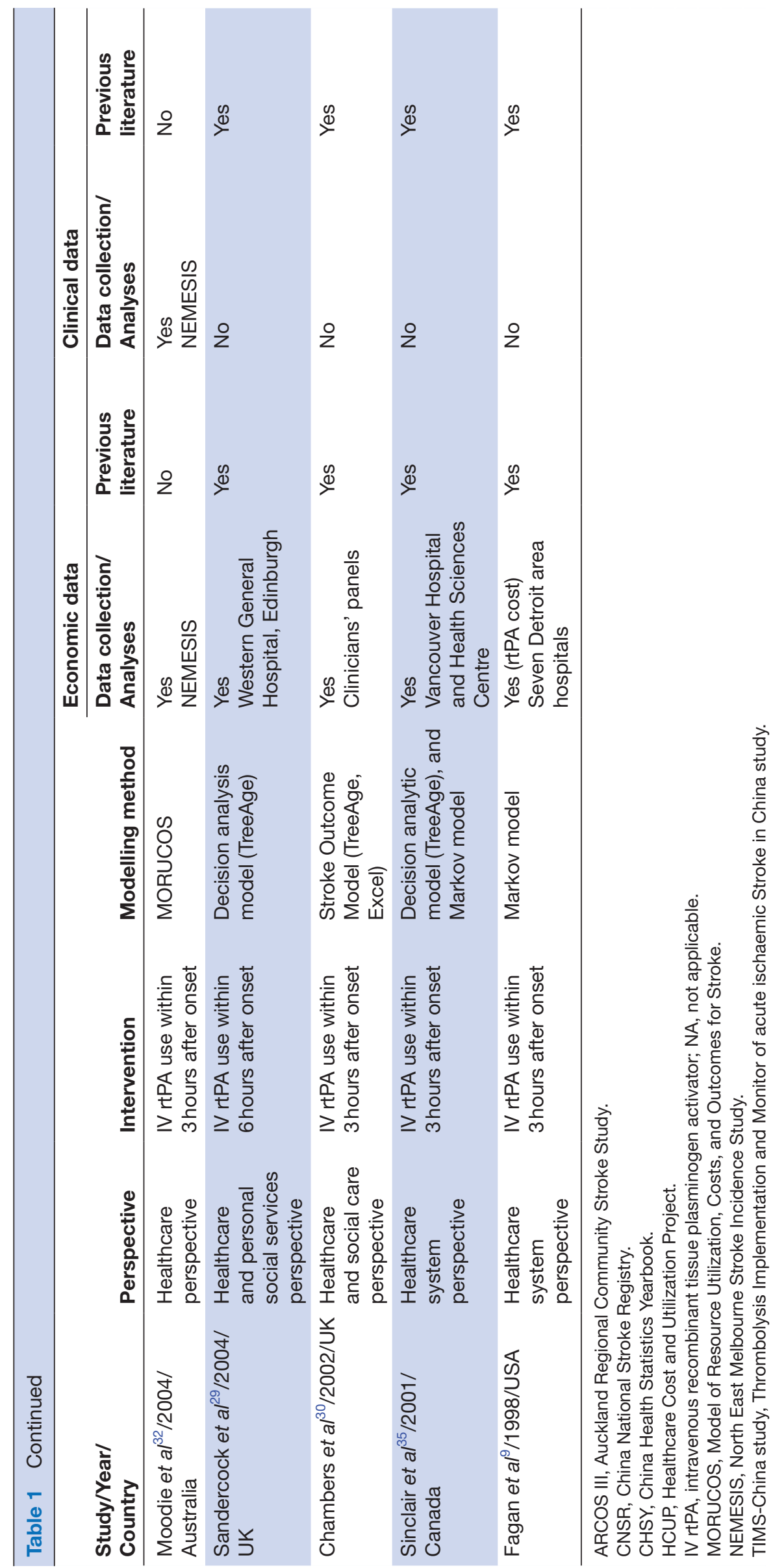




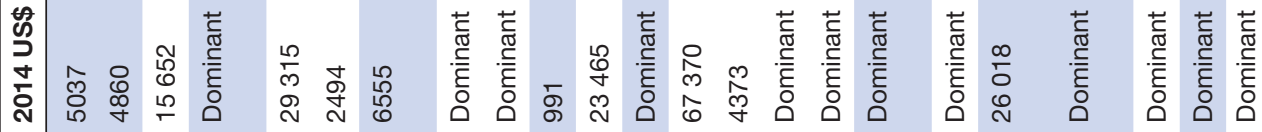

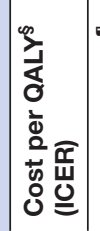

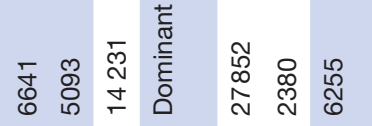

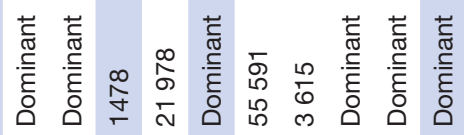

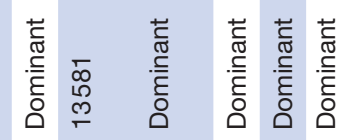
离 焉

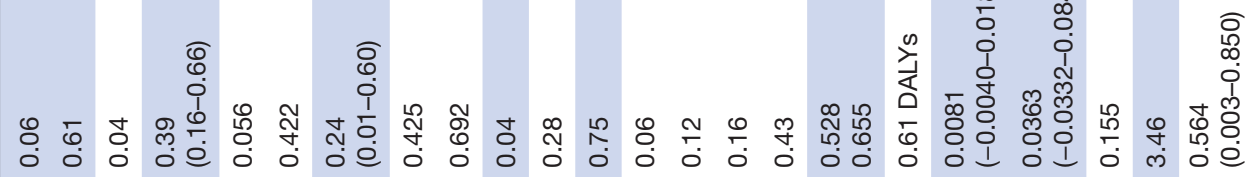

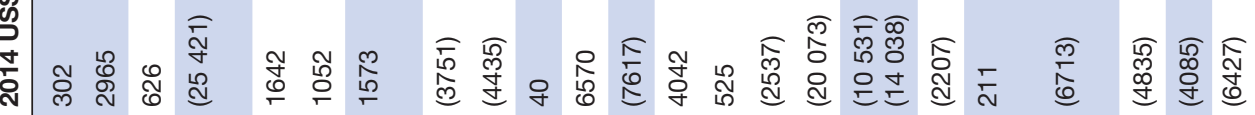

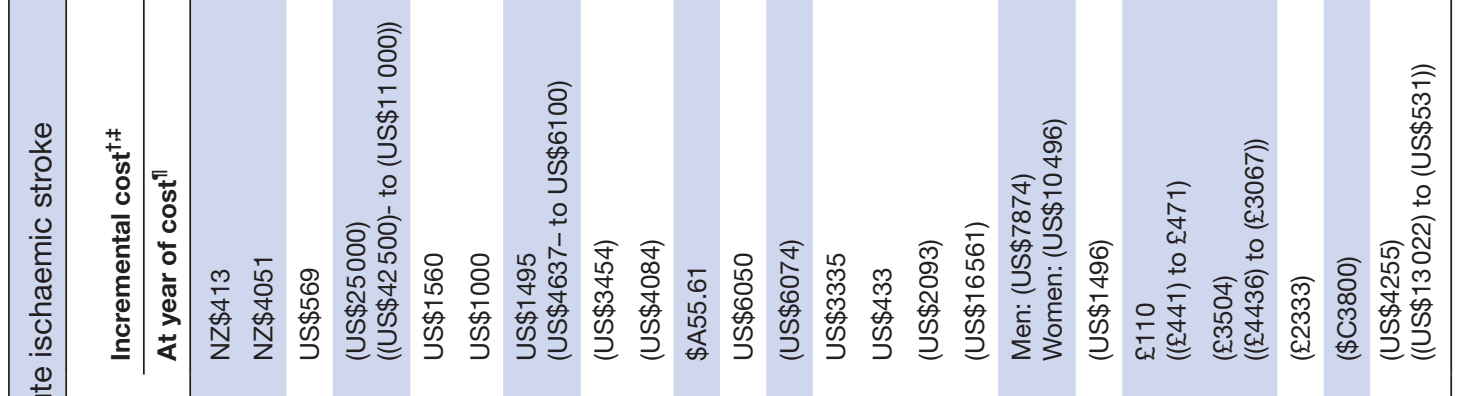

畩

穴

ஜ요욤
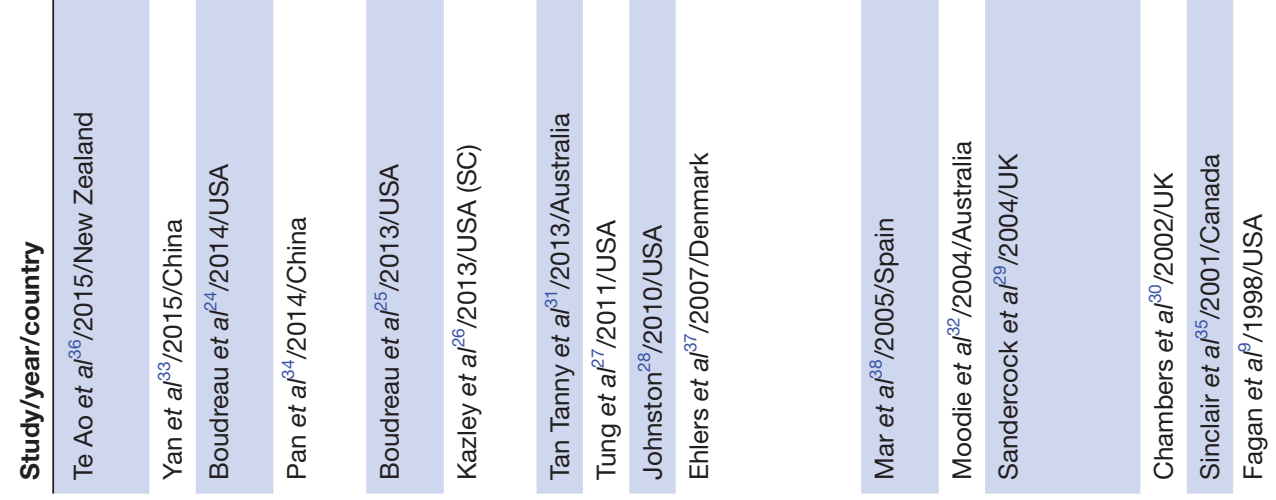


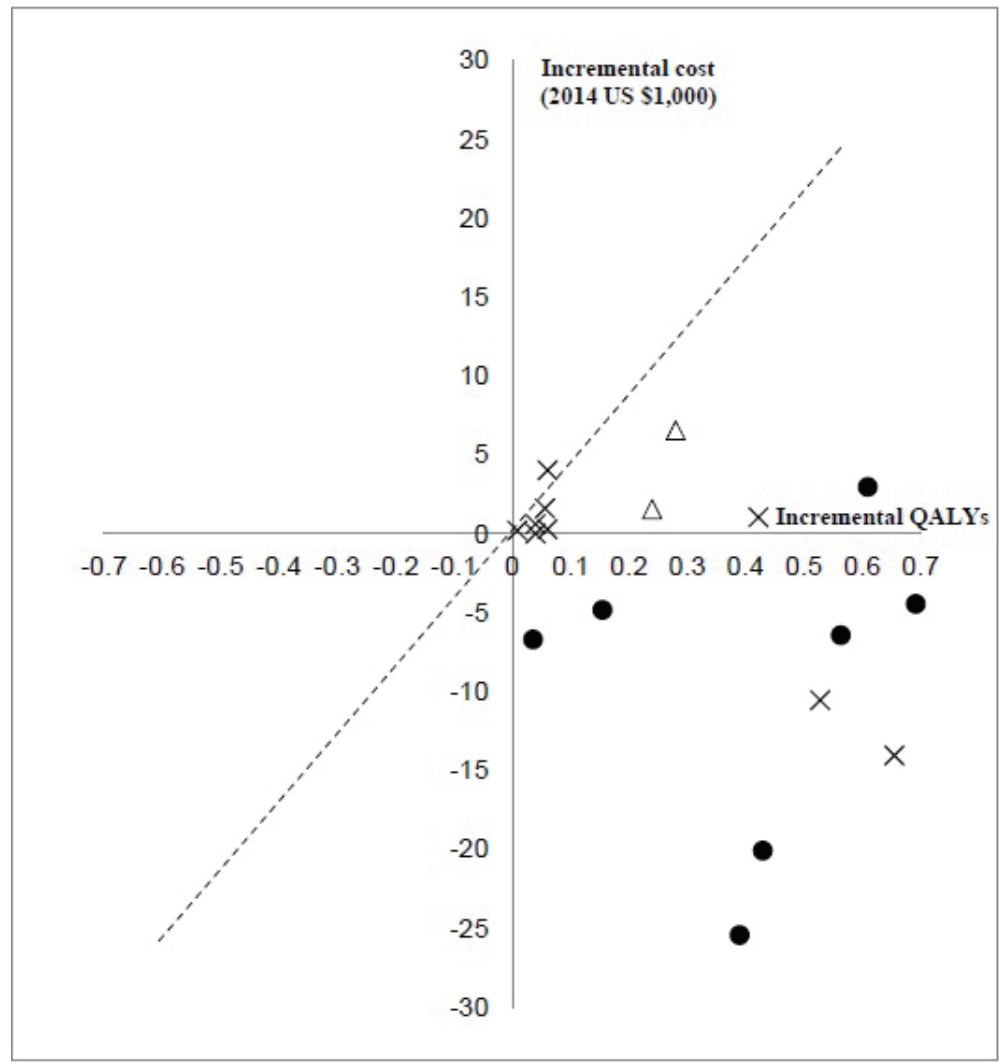

Notes:

$\mathrm{x}$ : The first year incremental costs and QALYs from rtPA therapy

$\Delta$ : Lifetime incremental costs and QALYs from rtPA therapy within 3-4.5 hours after onset of stroke

- : Lifetime or 30 years' incremental costs and QALYs from rtPA therapy within 0-3, 0-4.5, or 0-6 hours after onset of stroke

For studies with non-US currency, 2014 US dollar values were derived by using consumer price indices of study countries in the years of costs and in 2014 from the World Bank and purchasing power parity (PPP) exchange rate in 2014 from the Organisation for Economic Co-operation and Development (OECD). The ICER from Sinclair et al. was not shown in the graph because of limited space.(35) IV rtPA was a dominant strategy from Sinclair et al..(35)

Figure 3 Summary of incremental cost-effectiveness ratio (ICERs) of rtPA therapy from the literature. IV rtPA, intravenous recombinant tissue plasminogen activator; QALY, quality-adjusted life year.

In addition to time windows, some other factors may lead to heterogeneity in study results. For example, the study perspective affects the cost-effectiveness of IV rtPA. Healthcare payers' perspective considered only direct medical cost, while societal perspective included both direct medical cost and indirect cost, such as productivity loss and informal caregiving costs. IV rtPA is expected to decrease indirect costs associated with stroke, while IV rtPA is known as reducing the short-term disability rate. ${ }^{7-9} 25$ Considering indirect costs could improve the ICER for IV rtPA within 3-4.5 hours after stroke or make IV rtPA a dominant strategy. Time horizon may also significantly affect the cost-effectiveness of IV rtPA. All the studies consistently concluded that IV rtPA increased short-term (1 year) cost. However, IV rtPA reduced long-term cost (lifetime or 30 years) because of lower rehabilitation and disability-associated cost among patients with IV rtPA.
A main strength of reviewed studies is a timely research using the most recent available costs and outcomes from published secondary sources or primary data collection as inputs for evaluations. These inputs changed over time because of new medical technology for treating acute ischaemic stroke and updated recommendations or guidelines. After releasing the updated guidelines from AHA/ASA in 2009 and other organisations in Europe and Australia on the extended time window for IV rtPA therapy, ${ }^{13-16}$ a number of publications $(n=6)$ have examined the extended time window in the past 6 years.

Some common limitations of the studies, however, were also observed. One of the main limitations in the studies was that indirect costs, such as productivity loss and informal caregiving cost, were usually not included in the cost analyses. The proportion of indirect costs for stroke is significant. ${ }^{39}$ A literature review showed that 
Table 3 Major limitations listed in the cost-effectiveness studies of rtPA for acute ischaemic stroke

\begin{tabular}{|c|c|}
\hline Study/year/country & Limitations \\
\hline Yan et $a l^{33} / 2015 /$ China & $\begin{array}{l}\text { The medical costs did not include the cost after discharge } \\
\text { The study used charges not real costs } \\
\text { The study used data from a single hospital in China }\end{array}$ \\
\hline Boudreau et $a l^{24} / 2014 /$ USA & $\begin{array}{l}\text { The results were specific to the assumptions and the data used } \\
\text { QALYs were derived by using multiple inconsistent studies } \\
\text { Long-term cost, QALYs, disabilities and mortality data were limited and dated }\end{array}$ \\
\hline Boudreau et $a l^{25} / 2013 /$ USA & $\begin{array}{l}\text { The results are specific to the assumptions and the data used } \\
\text { The data are from numerous published studies including clinical trials }\end{array}$ \\
\hline Kazley et $a^{26} / 2013 /$ USA (SC) & $\begin{array}{l}\text { The study examined only a single state } \\
\text { The assumptions and data used in the study did not fully represent the clinical practise } \\
\text { situation } \\
\text { Data do not represent the current year } \\
\text { The study may underestimate the benefit because of previously validated model with } \\
\text { conservative estimates } \\
\text { The study only considered treatment within } 3 \text { hours after stroke onset (not up to } 4.5 \text { hours) }\end{array}$ \\
\hline $\begin{array}{l}\text { Tan Tanny et } a /^{31} / 2013 / \\
\text { Australia }\end{array}$ & $\begin{array}{l}\text { The study assumed that survival and quality of life would not change between } 90 \text { days and } \\
12 \text { months after stroke } \\
\text { Efficacy data were drawn from analyses of studies of rtPA being given between } 3 \text { and } \\
4.5 \text { hours (not rtPA within } 4.5 \text { hours) }\end{array}$ \\
\hline Tung et $a l^{27} / 2011 /$ USA & $\begin{array}{l}\text { Input parameters were best estimates from previously published data } \\
\text { The study did not model changes in functional status from causes other than stroke }\end{array}$ \\
\hline Johnston $28 / 2010 /$ USA & $\begin{array}{l}\text { The results depended on a single cost-utility analysis that required a number of uncertain } \\
\text { assumptions }\end{array}$ \\
\hline Sinclair et $a /^{35} / 2001 /$ Canada & $\begin{array}{l}\text { Short-term hospitalisation cost based on a small sample size of } 22 \text { patients from a single } \\
\text { centre (generalisability) } \\
\text { There was a difficulty in determining the costs of stroke care and services in Canada on a } \\
\text { 'per patient basis' } \\
\text { The study used a point estimate without a formal quantitative estimate of its precision }\end{array}$ \\
\hline Fagan et al ${ }^{9} / 1998 /$ USA & $\begin{array}{l}\text { The study used a placebo group from the NINDS rtPA Stroke Trial as the source of data for } \\
\text { some aspects of the cost analysis } \\
\text { The protocol precluded antithrombotic therapy in the first } 24 \text { hours after stroke onset, which } \\
\text { may affect cost and health outcomes }\end{array}$ \\
\hline
\end{tabular}

Three studies (Te Ao et al ${ }^{36}$ Moodie et al ${ }^{32}$ Sandercock et $a{ }^{29}$ ) did not list limitations.

NINDS, National Institue of Neurologic Disorders and Stroke; rtPA, intravenous recombinant tissue plasminogen activator; QALY, qualityadjusted life year.

the median proportion of indirect costs was $32 \%$ of the total cost of stroke. ${ }^{39}$ However, most studies chose the healthcare perspective or payers' perspective, which did not consider indirect costs. Moreover, studies using the societal perspective did not include indirect costs, ${ }^{26} 27$ or included informal caregiving cost only. ${ }^{38}$ None of the studies included productivity loss as a part of cost. When current cost-effectiveness models assumed an elderly cohort, productivity loss among stroke survivors may be negligible. However, stroke onset among young adults has been increasing ${ }^{40}$ and productivity loss could be a large burden for young stroke survivors with disabilities. For better cost-effectiveness evaluation, indirect cost should be considered as a part of cost in the analyses. 
Next, most of lifetime and long-term effectiveness data, including QALYs of disabled stroke survivors, incidence of recurrent stroke among stroke survivors and 1-year mortality, were limited as well as outdated, although all studies tried to use the most up-to-date data available. Most studies in the 2010 still used QALYs data from the 1990s studies. ${ }^{24-27}$ Although cost data, especially long-term cost data, could hardly be free from outdated data, the reviewed studies tried to use recent cost data or at least adjusted cost to current currency value by using consumer price index (CPI) to alleviate concerns regarding outdated data. Lastly, there were some inconsistencies because of using multiple data sources. For instance, QALYs by disability status were not well-developed in the literature. Thus, QALYs of disabled and non-disabled stroke survivors were obtained from different data sources. ${ }^{24}{ }^{25}$ In addition, most of the cost data were not collected within clinical trials, leading to a lack of consistency within a study.

Potential research areas to make up for these limitations as well as to improve the quality of research remain. Despite robust results from sensitivity analyses, developing high-quality data sources is still important for future efforts. Developing long-term follow-up trials among stroke survivors and research in long-term cost and effectiveness is most needed. Published large-scale effectiveness data from the real-world, including cost as a subcomponent, and studies which investigate those data are also needed. There are needs for indirect cost data and cost-effectiveness studies from the societal perspective to better understand societal impact of IV rtPA therapy. Concurrently, better models with multiple age cohorts would be useful to identify the impact of IV rtPA on different age cohorts. Boudreau et $a l^{25}$ partly show how much the ICER could be different by age. Another future research area would be to examine the impact of the age or severity of stroke on ICER of IV rtPA treatment.

There were few studies in middle-income countries, likely because of a lack of infrastructure to provide IV rtPA. The incidence of stroke in the middle-income world has increased since 1970 s, with $85 \%$ of stroke deaths worldwide occurring in middle-income countries. ${ }^{41}$ We found only two studies of cost-effectiveness of IV rtPA from middle-income countries. ${ }^{33} 34$ To better understand the cost-effectiveness of IV rtPA worldwide, more studies from countries in Africa, Latin America and Asia would be useful.

In this review, we did not include studies examining cost-effectiveness of strategies to improve the underutilisation of IV rtPA. Despite strong evidence of better clinical outcomes associated with IV rtPA, IV rtPA remains underutilised among patients with acute ischaemic stroke. ${ }^{42}$ Only $3.4 \%-5.2 \%$ of patients with stroke received rtPA therapy in the USA in $2009 .{ }^{43}$ Telestroke, air transport and certified stroke centres have been discussed as strategies to improve the utilisation of IV rtPA. The implementation of those strategies may improve IV rtPA utilisation but require additional costs. However, reviewed studies assumed that there were no additional costs to provide patient access to IV rtPA. Further cost-effectiveness studies including implementation costs are needed to support utilisation of IV rtPA.

\section{CONCLUSIONS}

This study found that the IV rtPA was a dominant strategy for those who received the therapy within 0-3 hours after the onset of stroke and a cost-effective strategy for those who received the therapy within 3-4.5 hours after stroke in long-term compared with traditional treatment for patients with acute ischaemic stroke without IV rtPA. This review provides considerable support for further development of interventions to promote IV rtPA use. To better evaluate cost-effectiveness of IV rtPA, establishing relevant clinical and cost data sources and developing evaluation, including programme costs, may be useful to improve the access to and use of IV rtPA.

Contributors HJ planned the project, performed review and wrote the manuscript. MGG helped plan the project, commented for medical issues and contributed to revising the manuscript. GW planned and supervised the project, and contributed to revising the manuscript.

Competing interests None declared.

Provenance and peer review Not commissioned; externally peer reviewed.

Open Access This is an Open Access article distributed in accordance with the Creative Commons Attribution Non Commercial (CC BY-NC 4.0) license, which permits others to distribute, remix, adapt, build upon this work non-commercially, and license their derivative works on different terms, provided the original work is properly cited and the use is non-commercial. See: http://creativecommons.org/ licenses/by-nc/4.0/

(c) Article author(s) (or their employer(s) unless otherwise stated in the text of the article) 2017. All rights reserved. No commercial use is permitted unless otherwise expressly granted.

\section{REFERENCES}

1. Krishnamurthi RV, Feigin VL, Forouzanfar $\mathrm{MH}$, et al. Global Burden of Diseases, Injuries, Risk Factors Study 2010 (GBD 2010)GBD Stroke Experts Group. Global and regional burden of first-ever ischaemic and haemorrhagic stroke during 1990-2010: findings from the global burden of disease study 2010. Lancet Glob Health 2013;1:e259-e281.

2. World Health Organization. The world health report 2002. Midwifery 2003;19:72-3.

3. Heidenreich PA, Trogdon JG, Khavjou OA, et al. American Heart Association Advocacy Coordinating Committee, Stroke Council, Council on Cardiovascular Radiology and Intervention, Council on Clinical Cardiology, Council on Epidemiology and Prevention, Council on Arteriosclerosis, Thrombosis and Vascular Biology, Council on Cardiopulmonary, Critical Care, Perioperative and Resuscitation, Council on Cardiovascular Nursing, Council on the Kidney in Cardiovascular Disease, Council on Cardiovascular Surgery and Anesthesia, and Interdisciplinary Council on Quality of Care and Outcomes Research. Forecasting the future of cardiovascular disease in the united states: a policy statement from the american heart association. Circulation 2011;123:933-44.

4. Gustavsson A, Svensson M, Jacobi F, et al. CDBE2010Study Group. Cost of disorders of the brain in Europe 2010. Eur Neuropsychopharmacol 2011;21:718-79.

5. Truelsen T, Begg S, Mathers C. The global burden of cerebrovascular disease. 2000 http://www.who.int/healthinfo/statistics/bod cerebrovasculardiseasestroke.pdf.

6. Jauch EC, Saver JL, Adams HP, et al. American Heart Association Stroke Council, Council on Cardiovascular Nursing, Council on Peripheral Vascular Disease, Council on Clinical Cardiology. Guidelines for the early management of patients with acute ischemic stroke: a guideline for healthcare professionals from the 
American heart association/American stroke association. Stroke 2013;44:870-947.

7. Saver JL, Gornbein J, Starkman S. Graphic reanalysis of the two NINDS-tPA trials confirms substantial treatment benefit. Stroke 2010;41:2381-90.

8. Saver JL, Yafeh B. Confirmation of tPA treatment effect by baseline severity-adjusted end point reanalysis of the NINDS-tPA stroke trials. Stroke 2007;38:414-6.

9. Fagan SC, Morgenstern LB, Petitta A, et al. Cost-effectiveness of tissue plasminogen activator for acute ischemic stroke. NINDS rt-PA stroke study group. Neurology 1998;50:883-90.

10. Demaerschalk BM, Hwang HM, Leung G. Cost analysis review of stroke centers, telestroke, and rt-PA. Am J Manag Care 2010;16:537-44.

11. Jung KT, Shin DW, Lee KJ, et al. Cost-effectiveness of recombinant tissue plasminogen activator in the management of acute ischemic stroke: a systematic review. J Clin Neurol 2010;6:117-26.

12. Tseng MC, Chang KC. Cost-effectiveness analysis of tissue plasminogen activator for acute ischemic stroke: a comparative review. Acta Neurol Taiwan 2004;13:149-55

13. Del Zoppo GJ, Saver JL, Jauch EC, et al. American Heart Association Stroke Council. Expansion of the time window for treatment of acute ischemic stroke with intravenous tissue plasminogen activator: a science advisory from the American heart association/American stroke association. Stroke 2009;40:2945-8.

14. European stroke organisation executive $\mathrm{C}$, committee ESOW. Guidelines for management of ischaemic stroke and transient ischaemic attack 2008. Cerebrovasc Dis 2008;5:457-507.

15. National Stroke Foundation. Clinical guidelines for stroke management 2010. Melbourne Australia, 2010. http:// strokefoundation.com.au/site/media/Clinical Guidelines Acute Management_Recommendations_2010.pdf.

16. National Institute for Health and Clincal Excellence. Alteplase for acute ischaemic stroke (NICE technology appraisal guidance [TA264], review of technology appraisal guidance 122), 2012. http:// www.nice.org.uk/guidance/ta264/resources/ta264-stroke-acuteischaemic-alteplase-information-for-the-public2.

17. Robinson R. Cost-effectiveness analysis. BMJ 1993;307:793-5.

18. Gold MR, Stevenson D, Fryback DG. HALYS and QALYS and DALYS, oh my: similarities and differences in summary measures of population health. Annu Rev Public Health 2002;23:115-34.

19. Robinson R. Cost-utility analysis. BMJ 1993;307:859-62.

20. Eichler HG, Kong SX, Gerth WC, et al. Use of cost-effectiveness analysis in health-care resource allocation decision-making: how are cost-effectiveness thresholds expected to emerge? Value Health 2004; 7:518-28.

21. Grieve R, Hutton J, Bhalla A, et al. A comparison of the costs and survival of hospital-admitted stroke patients across Europe. Stroke 2001;32:1684-91.

22. The world bank. http://data.worldbank.org/indicator/FP.CPI.TOTL.

23. Organisation for Economic Co-operation and Development. https:// stats.oecd.org/Index.aspx?DataSetCode=SNA_TABLE4.

24. Boudreau DM, Guzauskas GF, Chen E, et al. Cost-effectiveness of recombinant tissue-type plasminogen activator within 3 hours of acute ischemic stroke: current evidence. Stroke 2014;45:3032-9.

25. Boudreau DM, Guzauskas G, Villa KF, et al. A model of costeffectiveness of tissue plasminogen activator in patient subgroups
3 to 4.5 hours after onset of acute ischemic stroke. Ann Emerg Med 2013;61:46-55.

26. Kazley AS, Simpson KN, Simpson A, et al. Optimizing the economic impact of rtPA use in a stroke belt state: the case of south Carolina. Am Health Drug Benefits 2013;6:155-63.

27. Tung CE, Win SS, Lansberg MG. Cost-effectiveness of tissue-type plasminogen activator in the 3- to 4.5-hour time window for acute ischemic stroke. Stroke 2011;42:2257-62.

28. Johnston SC. The economic case for new stroke thrombolytics. Stroke 2010;41(10 Suppl):S59-S62.

29. Sandercock P, Berge E, Dennis M, et al. Cost-effectiveness of thrombolysis with recombinant tissue plasminogen activator for acute ischemic stroke assessed by a model based on UK NHS costs. Stroke 2004;35:1490-7.

30. Chambers MG, Koch P, Hutton J. Development of a decision-analytic model of stroke care in the united states and Europe. Value Health 2002;5:82-97.

31. Tan Tanny SP, Busija L, Liew D, et al. Cost-effectiveness of thrombolysis within 4.5 hours of acute ischemic stroke: experience from australian stroke center. Stroke 2013;44:2269-74.

32. Moodie ML, Carter R, Mihalopoulos C, et al. Trial application of a model of resource utilization, costs, and outcomes for stroke (MORUCOS) to assist priority setting in stroke. Stroke 2004;35:1041-6.

33. Yan X, Hu HT, Liu S, et al. A pharmacoeconomic assessment of recombinant tissue plasminogen activator therapy for acute ischemic stroke in a tertiary hospital in China. Neurol Res 2015;37:352-8.

34. Pan Y, Chen Q, Zhao X, et al. TIMS-CHINA Investigators. Costeffectiveness of thrombolysis within 4.5 hours of acute ischemic stroke in China. PLoS One 2014;9:e110525.

35. Sinclair SE, Frighetto L, Loewen PS, et al. Cost-Utility analysis of tissue plasminogen activator therapy for acute ischaemic stroke: a canadian healthcare perspective. Pharmacoeconomics 2001;19:927-36.

36. Te Ao B, Brown P, Fink J, et al. Potential gains and costs from increasing access to thrombolysis for acute ischemic stroke patients in New Zealand hospitals. Int J Stroke 2015;10:903-10.

37. Ehlers L, Andersen G, Clausen LB, et al. Cost-effectiveness of intravenous thrombolysis with alteplase within a 3-hour window after acute ischemic stroke. Stroke 2007;38:85-9.

38. Mar J, Begiristain JM, Arrazola A. Cost-effectiveness analysis of thrombolytic treatment for stroke. Cerebrovasc Dis 2005;20:193-200.

39. Joo H, George MG, Fang J, et al. A literature review of indirect costs associated with stroke. J Stroke Cerebrovasc Dis 2014;23:1753-63.

40. Kissela BM, Khoury JC, Alwell K, et al. Age at stroke: temporal trends in stroke incidence in a large, biracial population. Neurology 2012;79:1781-7.

41. Feigin VL, Krishnamurthi R. Stroke prevention in the developing world. Stroke 2011;42:3655-8.

42. Chapman SN, Mehndiratta P, Johansen MC, et al. Current perspectives on the use of intravenous recombinant tissue plasminogen activator (tPA) for treatment of acute ischemic stroke. Vasc Health Risk Manag 2014:10:75-87.

43. Adeoye $\mathrm{O}$, Hornung R, Khatri $\mathrm{P}$, et al. Recombinant tissue-type plasminogen activator use for ischemic stroke in the united states: a doubling of treatment rates over the course of 5 years. Stroke 2011;42:1952-5. 